\title{
PUPATION IN MYCETOPHILID FLIES: A CORRECTION
}

\author{
By William G. Eberhard \\ Smithsonian Tropical Research Institute and \\ Escuela de Biología, Universidad de Costa Rica \\ Ciudad Universitaria, Costa Rica
}

In a previous paper (Eberhard 1970) I made several claims regarding two species of the mycetophilid fly genus Leptomorphus: 1) the larval cuticle is not shed prior to pupation; 2) the last two and one half segments of the larva are discarded at pupation; and 3) the larval head capsule is engulfed by the pupa during pupation (Eberhard 1970). Recent, more detailed observations of Leptomorphus sp. have shown that points 1 and 3 are probably wrong, and this note is an attempt to present a more accurate account of pupation.

Observations were made during Sept. 1984 near San Jose, Costa Rica on larvae living on the undersurface of a fungus-covered board, where they inhabited silken sheets with slime trails similar to those of $L$. bifasciatus and $L$. subcaeruleus (Eberhard 1970). One observation of the process of pupation was made under a dissecting microscope. This larva hung on an approximately horizontal pupal line fastened at either end to a glass slide, and was observed from above (i.e. from the larva's ventral surface); occasionally I tilted the slide so as to check the larva in lateral view. Species identification in the genus Leptomorphus is not presently possible (R. Gagné, pers. comm.); voucher specimens of adults reared from the larvae observed are deposited in the U.S. National Museum.

\section{RESULTS}

The overall sequence of events was the same as that described for L. bifasciatus and L. subcaeruleus (Eberhard 1970) except that larvae were on lines for somewhat less than 24 hours before pupating. Although the head capsule was nearly engulfed by the swollen anterior portion of the larva's body when pupation began, it did not disappear. Instead, as the anterior end of the animal's body assumed

Manuscript received by the editor October 2, 1985. 
the new (pupal) shape, the head capsule moved smoothly posteriorly along the center line of the animal's ventral surface. The capsule paused briefly when it reached the "collar" or the anterior end of the band of silk that fastened the larva to the pupal line, then moved on smoothly, passing beneath the mat of silk threads holding the larva to the pupal line. As the head capsule neared the posterior end of the body, the cuticle there began to wrinkle during each contraction of the animal's body, also as noted previously (Eberhard 1970). When the posterior end of the pupa broke free from the remains of the larva, the head capsule was left as part of the mass of larval material that remained attached to the line. Careful dissections of some of these masses in water revealed the presence of not only the head capsule but also a long tubular sheath of very thin, transparent cuticle that bore the rows of dark denticles found near segmental boundaries on the ventral surfaces of larvae (Eberhard 1970). Thus the entire larval cuticle was shed during pupation, and the head capsule was not engulfed.

With respect to point 2 (posterior segments of larval body discarded during pupation), the new evidence does not clearly contradict previous descriptions. Several minutes prior to the migration of the head capsule to the posterior end of the larva, the last two and one half segments of the larva's body had darkened to a caramel brown color, and the material inside was amorphous and inert when viewed through the larval cuticle. In contrast, there were clear internal movements of well defined structures just anterior to this area, and it appeared that the posterior tip of the pupa had already formed and was being repeatedly pushed posteriorly against the inert brown material. When the larval cuticle was finally discarded (above), these posterior two and one half segments did not wrinkle or contract as did the rest of the larval cuticle, but retained their form, and the rows of denticles marking the segmental boundaries on their ventral surface remained clearly visible and as far apart as they had been in the intact larva.

\section{Discussion}

Probably the pupation process in the Leptomorphus species of previous reports was the same as that described here. The larval head capsule is small and partially transparent, and difficult to see without magnification. The observations of larval head capsules on 
the ventral surfaces of pupal abdominal segments (Eberhard 1970) probably represent cases in which the larval skin was only partially shed, and broke near the tip of the pupal abdomen.

It has been argued that silk attachments to larval cuticle should be shed along with the larval cuticle (Eberhard 1970, Malloch 1917). Although this seems reasonable, it is clearly not the case in Leptomorphus sp. How the larval skin is shed so smoothly without disturbing, as far as can be seen, the silk lines that form the only attachment of the animal hanging on its pupation line remains a mystery.

\section{ACKNOWLEDGEMENTS}

I am grateful to R. Gagné for kindly identifying specimens, and the Vicerrectoría de Investigación of the Universidad de Costa Rica for financial support.

\section{REFERENCES}

EberhaRd, W. G.

1970. The natural history of the fungus gnats Leptomorphus bifasciatus (Say) and L. subcaeruleus (Coquillett) (Diptera: Mycetophilidae). Psyche 77: 361-383.

MaLLOCH, J. R.

1917. A preliminary classification of Diptera, exclusive of Pupiparia, based upon larval and pupal characters, with keys to imagines in certain families, Part I. Bull. Ill. State Lab. Nat. Hist. 12(3): 161-407, pls. 28-57. 

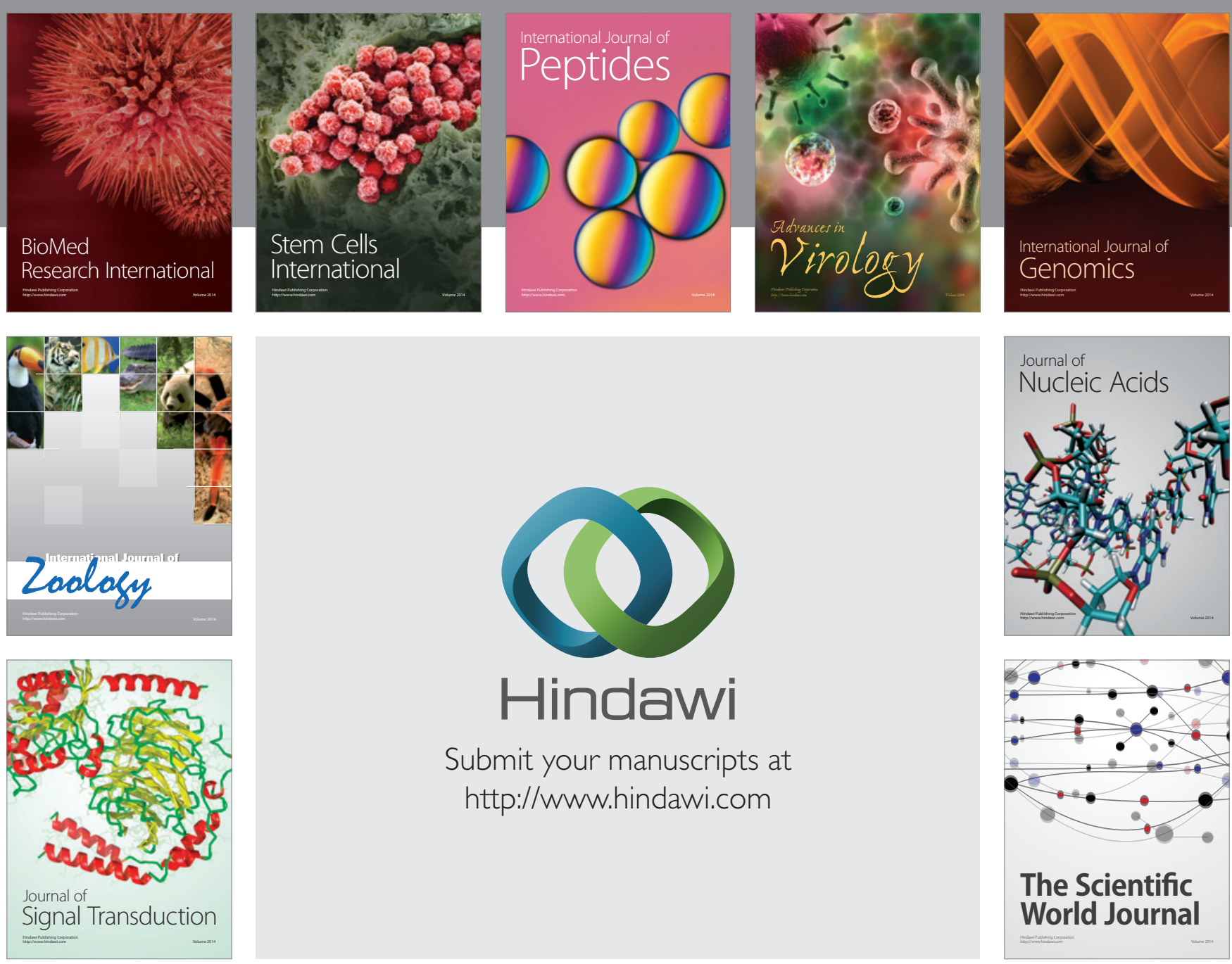

Submit your manuscripts at

http://www.hindawi.com
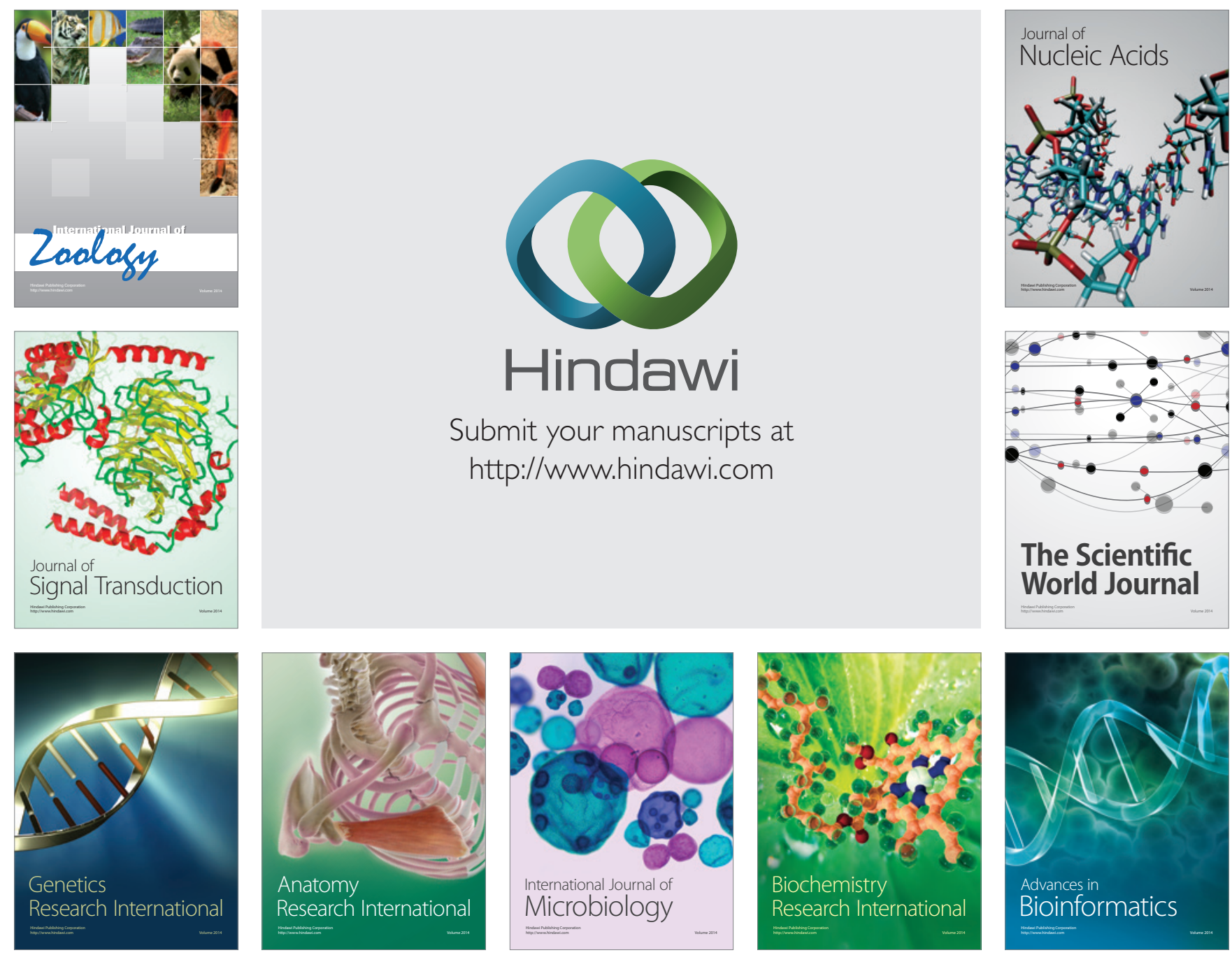

The Scientific World Journal
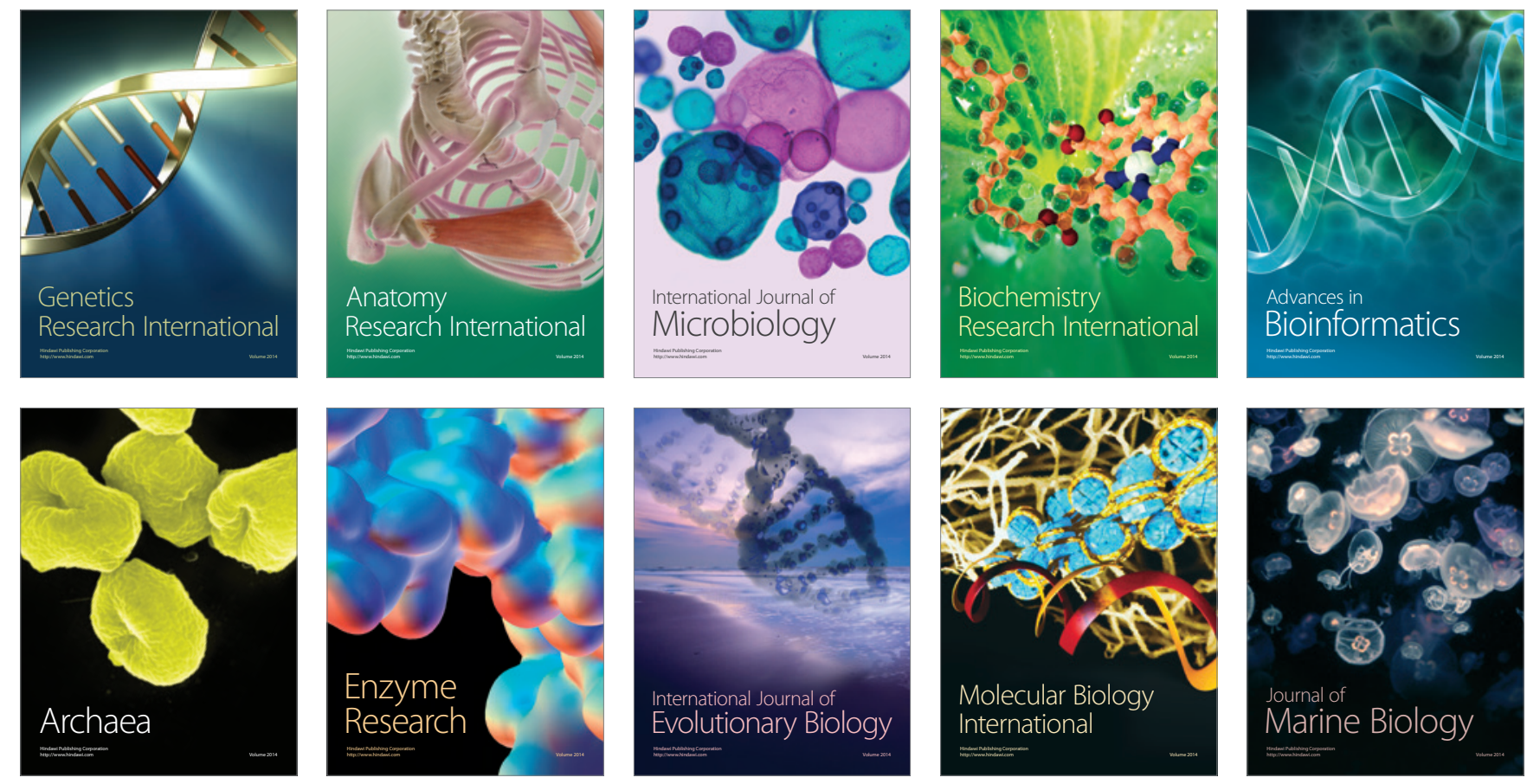